\title{
Conflict and Performance in Channels: A Comparative Synthesis of Empirical Findings
}

\author{
Kamran Eshghi \\ Ph.D. Student, Marketing \\ eshghik@mcmaster.ca
}

\author{
Sourav Ray* \\ Associate Professor of Marketing \\ sray@mcmaster.ca
}

\author{
Marketing Area \\ Degroote School of Business \\ McMaster University \\ Hamilton, ON, Canada
}

Working paper

Last Revision:

September 2015

* Contact Author

We gratefully acknowledge the generous help of several researchers who have shared their data with little urging. We would also like to thank Hamed Qahri-Saremi, and the participants of the May 2015 Value in the Vertical (VIV) Workshop and the Marketing BBL Seminar series at McMaster University, for their valuable comments and feedbacks. This research has been partially funded by research grants awarded to Dr. Sourav Ray by the Social Sciences and Humanities Research Council (SSHRC) of Canada. 


\title{
Conflict and Performance in Channels: A Comparative Synthesis of Empirical Findings
}

\begin{abstract}
We conduct a comprehensive meta-analysis of the literature on the role of channel conflict in channel performance. In particular, we assess the existing empirical evidence to compare two rival views of conflict. In the first view, conflict is a residual outcome of business processes that reduces joint profit and is efficiency depleting. Reduction or elimination of conflict is the firms' objective. In the second view, conflict is an inevitable part of the channel's business process and is a mediating construct that affects channel performance. Here the firms focus their efforts not so much on conflict "reduction" as on conflict "management" such as conflict resolution techniques to maximize business performance. We adopt the popular TrustCommitment and Interdependence models as our theoretical bases and the Intrachannel conflict model to integrate the empirical evidence on conflict, its antecedents, and consequences. We find that models in which conflict acts as a mediating construct outperform models in which conflict acts an outcome construct. We also find that models based on the Trust-Commitment perspective outperform models based on the Interdependence perspective in explaining the relationships among conflict, performance and some other key relational channel constructs. We base our conclusions on analyses performed using a two-stage meta-analytic structural equation modeling (TSSEM) technique.
\end{abstract}

Keywords: Distribution Channels; Channel Conflict, Channel Performance; Meta-analysis 


\section{INTRODUCTION}

Conflict and cooperation are linchpins of any business relationships and are often seen as key pillars for business performance. While this might be largely intuitive to most practitioners and readers interested in business to business marketing, the underlying drivers, manifestations, and impact are for the most part highly complex, defying any straightforward interpretations. However, given its salience in channel relations, significant managerial resources are invariably allotted to conflict management either directly or indirectly. For such allocations to be efficient in terms of return on efforts, appropriate interpretation of the research results is critical. Such interpretations are critical components of understanding the ecology of channel conflict, thereby leading to better managerial decisions. This has spurred several marketing scholars over the years to call for a deeper understanding of the role of conflict and cooperation in determining business outcomes in distribution channels (e.g. Antia et al. 2014; Gilliland, Bello, \& Gundlach, 2010; Rosenberg \& Stern, 1971; Rosenbloom, 2007). Therefore, it is hardly surprising that a literature survey of published work in marketing revealed over one hundred empirical papers since the 1960s that have focused on the construct "channel conflict" per se. Nevertheless, there still remain key questions around the construct, uncertainties around the robustness of some of the results, and the generalizability of the findings pertaining to performance. This paper is a partial effort to address some of these gaps.

For our purposes, channel "conflict" can be loosely understood as a consequential divergence of business incentives between one or more members of the channel. Of particular interest to us in this paper are two distinctly different views of the role of channel conflict in determining business performance in the channel.

In the first view, conflict could be a residual outcome of business processes that reduces joint profit and is efficiency depleting (e.g. Brown et al. 2006; Duarte \& Davies, 2003; Mohr et al., 1996; Morgan \& Hunt, 1994; Stern 1971). Thus, reduction or elimination of conflict is an objective of the firms; with cooperation and coordination being the counterpoints ( $c f$. Pearson \& Monoky, 1976; Schermerhorn, 1975). In spirit, this is similar to the modeling literature on channel coordination ( $c f$. Choi, 1991; Ingene \& Parry, 1995; Jeuland \& Shugan, 1983) where elimination of the divergent economic interests and maximizing joint channel profit can be seen as concurrent outcomes. For ease of referencing, we will call this "View 1".

In contrast, in the second view, conflict is an inevitable part of the channel's business process and is both temporally separated from, and only imperfectly predictive of, joint channel performance ( $c f$. Bradford et al. 2003; Menon et al. 1996). More specifically, conflict is viewed as a dynamic process with different stages (Pondy, 1967); conflict could be functional or dysfunctional (Rosenberg \& Stern, 1970; Rosenbloom, 1973); and conflict and cooperation are considered separate constructs (Ross \& Lusch, 1982; Samaha et al. 2011). The firm's effort is directed not so much to conflict "reduction" as to conflict "management", with a focus on conflict resolution techniques to maximize business performance (Chang \& Gotcher, 2010; Koza $\&$ Dant, 2007). Pondy's (1967) process framework has been used as an underlying foundation for many studies in this domain (e.g. Rosenberg \& Stern, 1971; Lengers et al. 2015). However, there are only a few empirical studies that explicitly examine this perspective in the context of interfirm relationships ( $c f$. Etgar, 1979; Frazier \& Rody, 1991; Koza \& Dant, 2007). For ease of referencing, we will call this "View 2".

The differences between the two views have important implications for managers tasked with relationship management in the channel. On one end of the spectrum, understanding the impact of conflict on performance allows managers to determine the opportunity costs of 
ignoring such conflict and thus, calibrate the scale of resources that can be deployed to conflict management. On the other end of the spectrum, understanding how conflict impacts performance, allows such managers to identify the appropriate covariates, intervention points, as well as intervention modes. In other words such an understanding could lead to better allocation of resources and choice of conflict management practices. In this, the two views offer rather distinct prescriptions. Unfortunately, there has been little systematic effort to assess existing empirical results in light of the differences engendered in the two views of conflict. In such circumstances drawing conclusions on the role of conflict in channel outcomes is fraught with uncertainties and incompleteness.

Nowhere is such uncertainty and incompleteness more significant, than in interpreting the relationships between channel conflict and channel performance. Despite the prodigious quantity of research on channels, our abilities to draw robust conclusions about these relationships is still quite tenuous at best. This is partly driven by the inherent differences between the two views of conflict that dominate published work. Consider the following.

Very few empirical studies in channels employ conflict as a focal construct, and most simply ignore its processual role as depicted by Pondy (1967) and Rosenberg and Stern (1970; 1971). Among the key theoretical perspectives deployed in empirical studies of conflict are the Trust-Commitment and Interdependence perspectives (Kumar et al., 1995; 1998; Morgan \& Hunt, 1994). Most of these are consistent with the first view of conflict as an outcome concurrent with that of performance. Taken together, these make it difficult to assess the impact of conflict on channel performance in these studies.

To add to the challenge, previous studies on conflict relate the construct to as many as 25 inter-firm constructs, often with inconsistent results across studies, limiting our ability to infer generalizability to the results. The challenges are particularly severe for assessing the relationship between conflict and channel performance. Some studies show that conflict reduces channel performance (Kumar et al., 1995; Kumar et al. 1992; Jap \& Ganesan, 2000; Ross et al. 1997; Web \& Hogan, 2002). However, several other studies show that conflict does not lead to a reduction in level of channel performance (Assael, 1969; Brown et al. 1983; Lusch, 1976). Authors such as Rosenbloom (1973) has tried to explain the confusion by contending that the relationship between these two constructs follows a non-linear inverted-U curve, where conflict is functional at moderate levels and destructive at very low or high levels. Taking the cue, other authors such as Brown (1980) build on Rosenbloom's work by asserting an additional layer of non-linearity where an upright U-shape curve is followed by the inverse U-shape curve.

Substantively, in this paper, we aim to assess the conflicting views of channel conflict as well as shed more light on the seemingly inconsistent findings at the heart of the conflict performance link. We adopt the Trust-Commitment and Interdependence frameworks (Kim \& Hsieh, 2003; Kumar et al,. 1995; 1998; Morgan \& Hunt, 1994) as our theoretical bases to guide our investigation. We then draw upon Rosenberg and Stern's (1971) intrachannel conflict model to synthesize the available empirical evidence.

Methodologically, we conduct a comprehensive meta-analysis with "conflict" as the focal construct. Meta-analysis has often been used in marketing particularly in channel setting in past decades over different important channel constructs such as trust, dependence, opportunism, and satisfaction (e.g. Crosno \& Dahlstrom, 2010; Geyskens et al. 1998; 1999, 2006; Palmatier et al., 2006; Scheer et al., 2014). Nevertheless, channel conflict remains largely understudied using this methodology. Given the fairly large empirical literature, we believe this method is best suited to synthesize the results of previous studies and resolve the inconsistency of results. To that end, 
we use the two-stage meta-analytic structural equation modeling technique within the broad confines of the Trust-Commitment and Interdependence models.

This study contributes to the marketing channels literature in four ways. First, to the best of our knowledge this is not only the most current but also the first meta-analysis focused on channel conflict and channel performance. ${ }^{1}$ Second, to the best of our knowledge, ours is the first effort to identify the significance of the two rival views of conflict in the context of channel outcomes. Our findings show that based on current empirical evidence, models in which conflict acts as a mediating construct (view 2) exhibit a higher level of goodness-of-fit and outperform models in which conflict acts an outcome construct (view 1). Third, we integrate the current stream of research on the relationship between channel conflict, channel performance and other important inter-firm relational constructs such as trust, commitment, satisfaction and interdependence. We assess the robustness of individual study findings; establishing several empirical generalizations in the process. We find that the empirical evidence broadly support a negative conflict-performance link, and that the Trust-Commitment framework outperforms the Interdependence framework in explaining the relationships among key channel constructs. Last but not the least, to the best of our knowledge, we are among the first in marketing to use the two-stage meta-analytic structural equation modeling technique. ${ }^{2}$ We believe this technique provides more accurate estimates than other techniques in vogue.

The rest of the paper proceeds as follows: We begin with a background review and theory sections in which we explain the two competing views and briefly explain the theoretical frameworks we deploy. Then, we present the research method and data analyses procedures. Subsequently, we report the results and discuss the significance and implications of the findings. We conclude with limitations and suggestions for further study.

\section{BACKGROUND}

The marketing literature on channel conflict has evolved significantly over the past few decades. The focus of studies in the 70's and 80's was on conflict and power constructs (Rosenberg \& Stern, 1970; Hunt et al., 1985). In the 90's with the emergence of relationship marketing the focus was redirected toward trust and commitment roles in inter-firm relationships. Papers in the past decade have continued to devote much attention to relationship marketing as well as dependence, and transaction costs related constructs (Anderson \& Weitz, 1992; Morgan \& Hunt, 1994; Kumar et al., 1995). In the new millennium, technological changes, especially the digital revolution and multiple marketing channel structures fostered by the Internet technology, have triggered a resurgence of scholarly interest in channel conflict (Webb, 2002). In this section we highlight two important aspects of this literature as part of this renewed interest in the domain: (1) Two competing views of Channel Conflict, and (2) Inconsistent results pertaining to the Conflict-Performance link.

\section{Two Competing Views of Channel Conflict}

In a very general sense, channel conflict can be seen as a consequential divergence of business incentives between one or more members of the channel. The "consequential" nature of the divergence is driven by the interdependence between channel members, where individual

\footnotetext{
${ }^{1}$ Geyskens et al`s (1999) meta analysis of channel relationships is the closest in spirit to our work. However, unlike us they do not focus explicitly on channel conflict, thereby limiting the conclusions they could draw in the domain.

${ }^{2}$ Verbeke et al. (2011) is the only other marketing paper we know. We elaborate more on the model in our paper.
} 
members' economic well-being is a function of not only one's own actions but also the actions of others in the channel. It is this externality that makes potential for conflict a constant in any channels context. Of course, such a potential would only call for managerial attention if it would have a meaningful impact on the economic performance of the channel members. The distinct differences in the manner in which one can view channel conflict, derive mainly from the degree of separation presumed between conflict and this economic performance. One view finds resonance in a zero-sum notion of conflict, where conflict concurrently reduces joint performance in the channel. The other view finds resonance in a notion where conflict and performance are related but are either separated or can be separated from the joint performance. These different perspectives naturally lead to different firm objectives vis-à-vis addressing conflict. The different perspectives also lead to different ways characteristics of conflict are conceptualized. The differences in the manner in which conflict is conceptualized in turn, naturally lead to different types and levels of managerial approach. To elaborate on what we see as the distinct differences between the two views of conflict, we now discuss the differences under the three interrelated themes: (a) Channel Objectives, (b) Conflict Characteristics, and (c) Managerial Approach.

(a) Channel objectives. When the notion of conflict is infused with a zero-sum notion, conflict is invariably seen as efficiency-depleting and by implication, performance-reducing. In a channel context, with interdependent outcomes, this reflects in reduced joint channel performance, reducing the size of the economic pie to be shared between the channel members (Pearson, 1973; Reve \& Stern, 1979). This can happen, say, when a reseller shirks on customer service to save costs, contrary to the manufacturer's wish to sustain a high level of such service. Such shirking could have a negative impact on the manufacturer's brand image and in turn negatively impact market shares of the brand. The last event would end up reducing the economic payoff for both channel members. The rational objective of the channel members in such circumstances should then naturally gravitate towards ensuring the joint channel profit is maximized by reducing conflict (Reve \& Stern, 1979). As should be clear from the example above, this is easier said than done; for the concurrency of conflict and performance in this view necessarily requires some level of coordination to reduce conflict and achieve higher performance. However, when conflict and coordination are on the extreme ends of the same continuum, reduction in one enhances another (Pearson \& Monoky, 1976). To a large extent, this view (View 1) motivates the Trust-Commitment and the Interdependence models of inter-firm relationships in the marketing and strategy literature (Van De Ven \& Walker, 1984; Anderson \& Weitz, 1992; Moorman et al., 1992; Morgan \& Hunt, 1994; Stern et al, 1996; Kumar et al., 1995; 1998; Zaheer et al., 1998; Hibbard et al. 2001). It also finds resonance in the modeling literature on channel coordination ( $c f$. Choi, 1991; Ingene \& Parry, 1995; Jeuland \& Shugan, 1983).

However, achieving coordination is costly, and especially so if channel members have already committed to a course of actions. So, this first view of channel conflict largely adopts a design perspective with an explicit objective to design channel and governance structures in order to eliminate or reduce the potential of conflict occurring (Ghosh \& John, 2012; Pearson \& Monoky, 1976; Robbins, Speh, \& Mayer, 1982). Various design approaches are deployed, spanning different levels of integration ( $c f$. Heide \& John, 1988; John \& Weitz, 1988), profit sharing schemes and incentives ( $c f$. Agrawal \& Lal, 1995; Bhardwaj \& Balasubramanian, 2005; Ingene \& Parry, 1995); as well as the setting of explicit superordinate goals as joint objectives ( $c f$. Hunger \& Stern, 1976; Sherif et al., 1961). The design put in place is expected to eliminate or reduce conflict only if it is appropriate to the particular circumstances at play. In case there is 
a lack of fit between the design and the business circumstances, it is expected to reflect in reduced performance through conflict driven inefficiencies.

In contrast to View 1 described above, the alternate view (View 2) explicitly separates conflict and performance. In this view, conflict and economic performance are not concurrently related; and it is not inevitable that conflict impacts joint performance. In fact, this view allows for conflict to be even beneficial. Given that conflict and economic performance is not intricately coupled, eliminating or minimizing conflict does not indicate the creation of higher joint value anymore. Consequently, the salience of conflict reduction as a channel objective takes a back seat to setting maximizing of the joint performance as a channel objective (Wernerfelt, 1994). Indeed, conflict reduction does not appear as an explicit objective at all.

The works of Pondy (1967) and Rosenberg and Stern (1971), where they frame conflict as a process, are examples of this line of thinking. By positing conflict as a process, conflict takes on a mediating role in determining channel performance. With the focus on joint channel performance, members address conflict in a sense and respond manner. The channel members' efforts are geared towards "managing" conflict as necessary, using resolution techniques apropos of the situation.

(b) Conflict characteristics. A key characteristic of conflict under View 1 is that conflict as an outcome is detrimental to channel efficiency (Pearson, 1973; Reve \& Stern 1979). Thus, conflict is something to be avoided and suppressed. A natural outcome of this view reflects in seeing conflict as the antithesis of cooperation (Pearson \& Monoky, 1976) which is the desired state of channel relations. Reduction in conflict naturally moves the channel towards greater cooperation.

In contrast, View 2 offers a more nuanced set of characteristics for conflict. First, as opposed to View 1 where it is seen as an outcome, conflict is seen as a process that has different episodes (Etgar, 1979; Pondy, 1967; Thomas, 1976). In particular, Pondy (1967), in his seminal work, proposes that conflict is a dynamic process with five distinct episodes: latent conflict, felt conflict, perceived conflict, manifest conflict, and conflict aftermath. Rosenberg and Stern (1971) subsequently use Pondy's framework to explain channel conflict. Second, in light of this expanded perspective, channel conflict can also be functional and is not to be only considered dysfunctional. Bradford et al. (2004) propose that conflict “... prevents stagnation, stimulates interest and curiosity in a task, and provides a medium through which problems can be aired and solutions arrived at." (p. 184). Third, by expanding the impact of conflict to include both positive and negative impact on performance, View 2 decouples conflict as a separate and distinct construct from cooperation. Indeed, this allows for both conflict and cooperation to operate at the same time.

The two views are also quite distinct from each other in terms of the underlying temporal characteristics. The dominant theme under View 1 is to focus on manifest conflict, and the perspective is mostly static. Conflicts certainly happen over time but only because business circumstances change, or there is a lack of fit between the design and the circumstances. This is as opposed to View 2 which takes an explicitly dynamic view of conflict, with conflict being explicitly seen as a sequence of episodes from the latent stage to manifestation (Pondy, 1967; Thomas, 1976).

(c) Managerial approach. The differences in the two views of conflict have important implications for the manner in which managers approach the business of managing conflict. Perhaps the most significant difference between the two views is forward-looking versus retrospective approach to conflict management they espouse. This finds resonance in Rosenberg 
(1974), who proposes that there exist two broad conflict measurement strategies: anticipatory and reactive.

In View 1, the general approach is to focus on the use of formal governance mechanisms and channel design to prevent conflict (Williamson, 1985). Therefore, the manager's task is to anticipate upcoming conflicts and to design the channel in a way that promotes cooperation by eliminating such conflict or at least curb the potential negative effects of conflict.

In contrast, in View 2, the managers' task is to learn from occurrence of conflict and apply that learning to future interactions in a performance-enhancing way. Thus, in this view, conflict management is an evolutionary process that is associated with piecemeal learning (Hunt, 1995).

The different views of conflict also infuse the managerial approaches with varying predispositions to seek different modes of cooperation. In View 1, managers are seen as focusing on working on gaining efficiencies in transaction costs by reducing conflict. Some of these efficiencies could come from increased levels of trust and commitment. However, the proactive focus on conflict reduction often incorporates techniques such as bargaining and politicking often associated with zero-sum outcomes (Dant \& Schul, 1992). Coupled with the more static view of conflict in View 1, this does not explicitly encourage the managers the time and degrees of freedom to work on building such relational outcomes such as trust and commitment.

In contrast, in View 2, managers are explicitly seen as working on maximizing the joint objective function by collaboration over conflictual issues to reach win-win outcomes (Koza \& Dant, 2007). It is in an incremental and evolutionary sense and respond manner that managers are expected to focus on integrative conflict management approaches such as joint problem solving to increase channel efficiency (Dant \& Schul, 1992). On the face of it, this approach leaves more room for focusing on the relational channel outcomes compared to View 1.

Last but not the least; the two views are different from each other in terms of the timeline of interventions to manage conflict. In View 1, conflict resolution does not happen in real-time. The assumption is that the design of the governance structure will suffice to prevent the occurrence of conflict, making real-time intervention largely moot.

In contrast in View 2, conflict resolution can happen in real time. Robbins et al. (1982) investigate the relationship between channel structure and level of conflict. While they find that vertically integrated structures do not necessarily result in low levels of channel conflict, the level of conflict depends on the specification of the managerial roles. When there are defined roles for managers who are empowered to intervene and manage conflict at each episode of conflict, it can result in enhanced channel performance. We summarize the two competing views in Table 1.

\section{$<$ Insert Table 1>}

\section{Inconsistent Results Pertaining to the Conflict-Performance Link}

A key aspect of the research interest in channel conflict has been the potential link between conflict and performance. This is not surprising given the time and effort spent in conflict management demand resources, and thus managers need to compute the cost-benefit tradeoffs. Performance here is primarily defined as financial business performance. Researchers have used various financial measures such as return on asset, sales, sales growth, and profit to assess performance in the context of inter-firm relations (Duarte \& Davies, 2003; Frazier et al., 1989; Lusch, 1976). While these studies have yielded a rich set of empirical results, there exist significant inconsistencies about the relationship between conflict and performance. 
Some studies show that conflict reduces performance ( $c f$. Kumar et al., 1995; Ross et al., 1997; Webb \& Hogan, 2002). This is the normal expectation derived from the view that conflict is efficiency depleting. However, other studies call these results to question, finding that conflict does not negatively affect performance ( $c f$. Assael, 1969; Brown et al., 1983; Lusch, 1976). Yet other studies actually show the positive effect. For example, Assael (1969) shows that conflict can enhance channel efficiency in the presence of equitable political and economic power among channel members.

In an attempt to explain the confusing array of relationships between channel conflict and performance, Rosenbloom (1973) contends that the relationship between these two constructs follows an inverted-U curve, where conflict is functional at moderate levels and destructive at very low or high levels. Brown (1980) complements the work of Rosenbloom by asserting that there is an upright U-shape curve that is followed by the inverse U-shape curve.

We conclude this section by noting that the two distinct views of conflict cast a shadow on not only our conceptualization of conflict but also on how we make sense of the managerial roles. Indeed, the competing views also bear on our understanding of the conflict-performance link, the empirical evidence about which is anything but conclusive.

\section{THEORETICAL FRAMEWORKS}

In order to achieve our key objective of empirically assessing the two views of conflict, we need to pin down the empirical results of the vast and somewhat fragmented literature on channel conflict in a manner that lends itself to objective comparisons. We also need to find a framework to meaningfully synthesize the research results for the comparisons. To these ends, we first adopt the Trust-Commitment and Interdependence perspectives as our conceptual framework (Kumar et al., 1995; Morgan \& Hunt, 1994; Palmatier et al., 2007). We then draw upon the Rosenberg \& Stern (1971) intra-channel conflict framework to synthesize the empirical results in a meaningful way. Our choices in this matter are derived from four main factors: (i) the Trust-Commitment and Interdependence perspectives are key theoretical models for studies in this arena; (ii) the construct "conflict" is explicitly used in several empirical studies based on these theories (Palmatier et al., 2007), which makes it possible to generate a large enough sample of papers to base our comparisons on ${ }^{3}$; (iii) the similarity of the manner in which "conflict" appears in the models, affords us an ability to design appropriate controlled experiments to compare and contrast the empirical results in the context of the meta-analysis methodology; (iv) The Rosenberg and Stern (1970) paper draws inspiration from the classic Pondy (1967) paper that has motivated several papers that followed in the domain, and offers an early effort at synthesizing the literature which is both flexible and general enough for our purposes; we anticipate this will aid in any future efforts by other researchers to build on our own results in the current paper.

We now present brief explanations of the frameworks that motivate our theoretical approach, as a lead-in to explaining our method in more details.

\footnotetext{
${ }^{3}$ Other theoretical perspectives such as Transaction Cost Economics (TCE) and Resource-Based View (RBV) theory have also been used to explain and predict inter-firm relationship, but the construct "conflict" has not been used in these perspectives as much as in Trust-Commitment and Interdependence perspectives.
} 


\section{The Trust-Commitment Perspective}

As per the Trust-Commitment perspective, relationship performance is determined by the level of buyer's trust in and/or commitment to a seller (Morgan \& Hunt, 1994). In comportment with View 1, conflict is seen as one of the key outcomes of the inter-firm interactions. Trust is modeled as affecting relationship performance, including conflict, directly or indirectly through commitment.

In keeping with the relational exchange ethos, initiating, maintaining and avoiding conflicts in the relationships are considered key endeavours of channel members, and trust is seen as the main ingredient that helps them achieve this (Balliet \& Van Lange, 2013). However, there are several ways trust has been defined, with Morgan and Hunt's (1994) definition of trust as "confidence in an exchange partner's reliability and integrity" (p. 316) offering a relevant interpretation in our channel context. Despite the multiplicity of definitions of trust, most definitions of trust revolve around expectations, predictability and confidence in other's behavior (Balliet \& Van Lange, 2013), which allows comparisons in our aggregate approach.

Commitment, on the other hand, is more about expectations of relationship continuity. For example, Moorman et al. (1992) define commitment as "an enduring desire to maintain a valued relationship" (p. 316). Dwyer et al.'s (1987) definition of relational continuity in interfirm relationships is also similar.

Trust has also been shown to lead to a greater level of commitment and satisfaction in inter-firm contexts (Poppo \& Zenger, 2002). The exchange outcomes of conflict and cooperation can be positively affected by trust and commitment, if both parties are willing to act in a way that leads to satisfaction of the committed and trusted exchange partner (Anderson \& Weitz, 1992; Hibbard et al., 2001). Relating trust directly to conflict, Zaheer et al. (1998) also show that trust partially reduces the intensity of conflict in the inter-firm interactions and encourage both parties to initiate cooperation (reduce conflict) in a mutual manner (Deutsch, 1958). Panel (a) of Figure 1 represents the traditional Trust-Commitment framework.

\section{The Interdependence Perspective}

The Interdependence perspective derives its inspiration from the power and conflict paradigms of inter-firm relationships. The key motivator of this perspective is the interdependence of channel members in performing channel tasks (Kim \& Hsieh, 2003; Stern et al., 1996; Kumar et al., 1995; 1998). Interdependence and drive for autonomy provide motives for both cooperation and conflict in a channel setting (Van De Ven \& Walker, 1984). The more interdependent the parties, the more likely they have to resolve their problems and converge their interests. Thus, interdependence also mediates the effect of trust and commitment on the exchange outcomes, such as conflict. Conflict is therefore seen as a consequence of the interdependence in channel settings (Zhou et al., 2007). So, the canonical form of this perspective also comports to View 1.

Jap and Ganesan (2000) show that (mutual or dyadic) interdependence plays a critical role in predicting inter-firm relationship and exchange outcomes. Papers such as Frazier (1999); Frazier \& Rody (1991); Kumar et al. (1995); etc. investigate the role of the magnitude of such interdependence on inter-firm performance outcomes and conflict, particularly in a channel setting. The broad findings of these studies show that interdependence positively affects the exchange outcomes because both parties are eager to maintain the relationship and resolve the conflict (Hibbard et al., 2001). Nevertheless, the empirical results are not unequivocal, for some 
other studies show that interdependence actually increases conflict ( $c f$. Brown et al., 1983; Frazier et al., 1989). Panel (b) of Figure 1 shows the traditional Interdependence framework. $<$ Insert Figure 1 here>

\section{Rosenberg and Stern's (1971) Model of Intra-channel Conflict}

Note that both the Trust-Commitment and the Interdependence perspectives can be seen to comport to View 1 where channel conflict is primarily seen as an outcome of the channel process. On the other hand, Rosenberg and Stern's (1971) model of intra-channel conflict presents a counterpoint by conceptualizing conflict as a mediating variable, in comportment with View 2. They model conflict as part of a process with three elements: sources, conflict level, and outcomes of conflict. This is represented in panel (a) of Figure 2. Several papers empirically explore the sources and outcome constructs under the broad rubric of this model (Brown, 1980; Etgar, 1979; Lusch, 1976; Reve \& Stern, 1979). Typical sources that have been investigated are goal incompatibility, drive for autonomy, and interdependence; while outcomes studied include satisfaction and financial performance. Of particular interest to us is that many of these constructs are also part of the constructs studied under View 1. This overlapping set of variables offers an opportunity to compare the aggregate empirical results of views 1 and 2 .

<Insert Figure 2 here>

We proceed with such a comparison in two stages. In the first stage, we identify the overlapping common constructs in the empirical studies that predominantly employ the TrustCommitment or Interdependence perspectives. In these conflict is an outcome variable. In the second stage, we "customize" the two models by changing the causal ordering of constructs to match Rosenberg and Stern's (1971) framework. In this customized setup, conflict is considered a mediator in the Trust-Commitment and Interdependence frameworks. We represent these in panels (b) and (c) of Figure 2. Therefore, we have four main models - the original TrustCommitment and Interdependence models (Figure 1) and the two corresponding customized models (Figures $2 \mathrm{~b}-\mathrm{c}$ ). We draw our conclusions by comparing these models. ${ }^{4}$

\section{METHOD}

\section{Data Collection}

Our main statistical approach for this study is meta-analytic structural equation modeling. We also conduct pairwise correlation analyses to synthesize the inconsistency regarding conflictperformance relationship.

The first step in both methods is to locate and identify the primary studies in which channel conflict is used. For this, we conduct a detailed bibliographic search of all empirical studies appearing in the marketing and management literature and that reported on relationships between channel conflict and other channel constructs that were identified by the queries. We searched for studies by using terms such as conflict, dispute, or any similar words that convey conflict. The literature search covers the 1960-2015 period. The following resources were searched for this purpose: ABI/INFORM, Google Scholar, and Social Sciences Citation Index, and issue-by-issue searches of important marketing and management journals such as the Academy of Management Journal, Journal of Marketing, Journal of Marketing Research, Journal of Retailing, Management Science, Marketing Science, Organization Science, Strategic

\footnotetext{
${ }^{4}$ Note that for the comparison we are not motivated by any specific directional hypotheses. Our operating null is that the aggregate effect sizes observed in existing studies do not pick a clear favorite between Views 1 and 2.
} 
Management Journal, and the Proceedings of the Academy of Management and American Marketing Association.

One of the challenges of studies such as these is to ensure that most of the relevant studies have been scanned. There is no foolproof way to ensure that. However, because we used search engines and academic databases such as Google Scholar, ABI/INFORM, and Social Science Research Network (SSRN), we have a high degree of confidence that we were able to capture most of the published papers and studies that investigated the relationship between conflict and other related channel constructs. We also checked the cited papers in each study to uncover more related studies in which researchers used conflict. To prevent the "file drawer problem" that is inherent in meta-analysis method (Rosenthal, 1979), we identified doctoral dissertations that are indexed in UMI Dissertation Abstract. ${ }^{5}$ Moreover, we contacted several authors with requests for correlation tables and other statistics not reported in their published studies. In particular, we contacted 35 authors and of the 27 responses received, 23 provided the required information. We also sought unpublished and forthcoming papers by posting a request on ELMAR, a listserv dedicated to marketing scholars. Accounting for multiple samples in a single study, our search generated 101 samples from 74 empirical studies. We collected data for 25 channel and interfirm constructs including conflict. This yielded a total of 232 correlations with a total aggregate $N$ of 19,003 . However, we had to a further paring of the sample for purposes of robustness. For a construct to be included in a meta-analysis using structural equation modeling, we need that construct to be related to every other constructs in the model (Brown \& Peterson, 1993). Specifically, we need at least three correlation coefficients for each pair of constructs for our structural equation modeling (see Palmatier et al., 2006; Scheer et al., 2014). So we excluded studies when we did not have at least three correlation coefficients for each pair of constructs. ${ }^{6}$ This resulted in retaining 152 out of the 232 correlation coefficients related to the relationship of conflict with other constructs. The final sample included six constructs (conflict, trust, commitment, interdependence, performance, and satisfaction) that were usable for our metaanalysis. ${ }^{7}$ The full list of papers that are used in this study is reported in Appendix B.

Despite our best efforts to identify and collect all conducted studies regarding conflict, we acknowledge the possibility that we might still have missed some, possibly biasing our results toward published papers with significant results. Therefore, for checking the robustness of our results we used several different tests. These included both the "failsafe $N$ " tests proposed by Rosenthal (1979) and Orwin (1983), as well as the "funnel plot" test of Rothstein, Sutton, \& Borenstein (2006). The results of these tests failed to reject the null hypothesis of no bias. We report the failsafe $N$ s of Rosenthal (1979) in Table 2 while we discuss details and results of the other methods (Orwin's failsafe $N$ and sample of funnel plot) in Appendix A.

\footnotetext{
${ }^{5}$ The "file drawer problem" refers to the bias induced in any meta-analyses due to over reliance on published studies. In general, papers where the key null hypotheses are not rejected; rarely get published.

${ }^{6}$ This also reduced the set of constructs we could use in our paper. The pairwise correlation analyses of conflict and the excluded constructs are available from the authors upon request. Four studies were excluded because the corresponding correlation matrices were not positive-definite.

${ }^{7}$ Following Geyskens et al. (1999), we cumulate similar constructs into overarching ones. Appendix A lists what we use for the key constructs conflict and performance. The complete list is available from the authors upon request.
} 


\section{Two Stage Meta-Analytic Structural Equation Modeling (TSSEM)}

For our analyses comparing the different frameworks, we adopt the two-stage metaanalytic structural equation modeling (TSSEM) technique proposed by Cheung and Chan (2005). This approach combines traditional meta-analysis techniques with a structural equation modeling (SEM) techniques.

There are different versions of such combined methods. One of the more popular ones is the Meta-Analytic SEM (MASEM) method of Viswesvaran and Ones (1995). Our choice of Cheung and Chan's $(2005 ; 2009)$ TSSEM method for the analyses is largely motivated by their discussions of the advantages of TSSEM over MASEM. ${ }^{8}$ The advantages they enumerate include: (a) TSSEM addresses certain limitations of diagnosticity inherent in interpreting MASEM results: TSSEM is based on the covariance matrix while MASEM is based on correlations under the assumption that elements of pooled correlation matrix are independent. In case of a poor fit of the model, MASEM cannot untangle whether it is due to lack of independence among elements of pooled correlation matrix or it is due to a poor model. (b) TSSEM addresses some inherent limitations of MASEM in interpreting goodness of fit indices: Cheung and Chan (2005) point to some problems in the interpretation of Chi-Square and fit indices when the pooled correlation matrix is used as the input of SEM instead of the covariance matrix. (c) TSSEM is better able to control for sampling variations: Since TSSEM uses the asymptotic covariance matrix, which incorporates information about sampling variation, it can control for large and small sampling variations, unlike MASEM.

\section{ANALYSES AND RESULTS}

We analyze the collected correlation coefficients in a two-stage process. In the first stage, we first obtain both the pooled correlation matrix and asymptotic covariance matrix (ACM) (Cheung \& Chan, 2005). The values of the ACM are used to correct the pooled correlations in the second stage of analysis. ${ }^{9}$ We then control for any heterogeneity across the studies, as explained below.

In studies such as our meta-analysis, one of the concerns is whether the effect sizes systematically vary across the studies used. The typical way to approach this is to include either a fixed-effect (FE) or a random-effect (RE) parameter in the model specification. Both models allow controlling for study-specific effect sizes. However, the FE model assumes a common effect across the studies while the RE model assumes that the observed effect sizes are drawn from a distribution of multiple realizations of the studies. It is impractical to argue for a common fixed effect across the sample of our studies. These studies involve different samples, different contexts, different temporal periods, and often different frameworks. As such, RE seems to be more appropriate. Regardless, in order to also have an empirical basis to select one model over the other, we explore which offers the better fit for the data (Cheung, 2013). The results of the first stage analysis (confirmatory factor analysis) show that the RE model (TLI=.208, CFI=.215, RSMEA=.180) is a better fit over the FE model thus vindicating the theoretical rationale. ${ }^{10}$

\footnotetext{
${ }^{8}$ See Cheung $(2005,2009)$ for more details of the presumed advantages. Nevertheless, TSSEM is a mixed bag. As Landis (2013) points out, combining meta-analysis and SEM has the limitations and advantages of both methods.

${ }^{9}$ Following Landis (2013), we use the total sample size instead of the harmonic mean for these estimations.

${ }^{10}$ The null of homogeneous effect sizes across studies is rejected when Tucker-Lewis index (TLI) and Comparative fit index (CFI) is $\leq 0.9$, and the root mean square error of approximation (RMSEA) is $\geq 0.08$ (Meyers et al., 2006).
} 
We used the pooled correlation matrix and the asymptotic covariance matrix from the first stage of TSSEM, and the aggregated sample size of all studies to conduct SEM analysis in the second stage. We employed Weighted Least Squares (WLS) or Asymptotically Distribution-Free (ADF) estimation method for fitting the model (see Browne, 1984 for details). We used OpenMx and metaSEM packages of R (version 3.1.3) to conduct the SEM analysis (Boker et al., 2011; Cheung, 2013; 2014).

\section{Pairwise Analyses}

We adopt the pairwise analysis approach to pin down the empirical relationships between the key constructs. We start by recording the reported sample size, correlation coefficients, and reliability of constructs in the studies. For purposes of rigor, construct pairs are only analyzed when the sample includes at least three raw effects for that pair (see Scheer et al., 2014). Unfortunately, not all studies report correlations. For such studies, we converted Student's t and F ratios to correlation coefficients using the formulas provided by Hunter and Schmidt (1990) (see Appendix A). Whenever we could not extract correlation coefficients from papers directly, we approached the authors requesting that information. Of the 23 responses received, 13 had the relevant, usable information (correlation tables and reliabilities). We include these in our sample. In two other papers for which we had the relevant variables but did not have the required information, we were able to impute effect sizes by converting standardized regression coefficients into correlation coefficients using the method suggested by Peterson and Brown (2005) (see Appendix A). In this manner, across 74 studies comprising 101 samples, we were able to generate 232 correlations for our analyses.

Since we include constructs from different studies, we are faced with a methodological challenge of comparing different error regimes. Therefore, we corrected the raw effect sizes for measurement error by dividing the correlation coefficients by the product of the square root of the reliabilities of the two constructs (Hunter \& Schmidt, 1990) (see Appendix A). When we did not have access to reliability due to lack of report or when the item is measured using single item, we used the mean reliability for that construct across all other studies (Geyskens et al., 1998; Scheer et al., 2014).

Lastly, we have to standardize the correlations for comparability across the studies. In particular, since some study measures are more precise than others, there is a need to control for study precision. The unstandardized corrected correlation coefficient has problematic standard error formulation (Rosenthal, 1994). For this, we converted the corrected correlation coefficients into Fisher's z scores. The Fisher's Z scores were averaged and weighted by an estimate of the inverse of their variance to give greater weight to more precise estimates. The overall average can be converted back into correlation coefficient with the inverse $\mathrm{Z}$ transformation (Hedges \& Olkin, 2014). ${ }^{11}$ We need the "transformed-back correlation $r$ ", to conduct other required tests such as Q homogeneity test and power analysis. We find all of the "standardized" pairwise correlation coefficients are significant at $\mathrm{p}<.01$.

Q statistic indicates whether the assumption that all of the effect sizes are estimating the same population mean is a reasonable assumption (i.e., examining statistical heterogeneity). ${ }^{12} \mathrm{Q}$

\footnotetext{
${ }^{11}$ The formula for Fisher's $\mathrm{z}$ is: $z=\frac{1}{2} \operatorname{Ln}\left[\frac{1+r}{1-r}\right]$. Typically, $(\mathrm{N}-3)$ is used to approximate variance to weight the $\mathrm{z}$ scores. The formula for the transformed back correlation is: $r=\left(e^{2 z}-1\right) /\left(e^{2 z}+1\right)$.

${ }^{12} \mathrm{Q}$ statistic is calculated as follows: $Q=\sum\left(\right.$ Weight $\times$ effect size $\left.(r)^{2}\right)-\frac{\left[\sum \text { (weight } \times \text { effect size }(r)\right]^{2}}{\sum \text { weight }}$
} 
is distributed as Chi-Square and if rejected, the distribution of effect sizes is assumed to be heterogeneous. The obtained Q statistic is significant for each pairwise relationship, indicating substantial variation (heterogeneity) in effect sizes across studies, which may be explained by other constructs that are absent from study. We report different types of observed and calculated correlations, as well as Q and other related meta-analytic statistics in Table 2.

\section{<Insert Table 2>}

We also calculated the $I^{2}$ heterogeneity index which indicates what proportion of total variation in the pooled effect sizes is due to heterogeneity among primary studies (Higgins \& Thompson, 2002) ${ }^{13}$. The index is neutral to the number of studies and as such is expected to be more accurate measure of the impact of study heterogeneity on effect size estimates, compared to the traditional Q-statistic. We report the $I^{2}$ values for all correlations in Table 3. Furthermore, because we used random-effect model in conducting our meta-analytic SEM, we considered the effect of asymptotic covariance matrix, which captures heterogeneity that exists in the pooled correlation matrix based on the variance among effect sizes (Cheung \& Chan, 2005).

<Insert Table 3 here>

It is also important to test whether the computed correlations (the transformed-back values, $r$ ) in primary studies are significantly different from zero (Hedges \& Pigott, 2001). For this, we conducted a power analysis based on the procedure proposed by Cohen (1988, 75-95). We analyzed the power for the 15 effect size estimates in our study. Power analysis results show that all power values are higher than the threshold (.80) for all the $r$ values in our study. In other words, all correlations are significantly greater than zero.

\section{SEM Analysis}

The pairwise correlation analysis reveals the statistical relationship between constructs in our model, but it does not allow us to infer how these constructs are related within a nomological network. Therefore, we used the TSSEM procedure as applied in Cheung $(2013,2014)$ to analyze the associations in more detail and compare the two competing views of conflict. Recall that there are four main models. The first two are the original Trust-Commitment and Interdependence models in which conflict is an outcome variable while the last two are what we call the "customized" models of Trust-Commitment and Interdependence perspectives where conflict is a mediating variable.

To compare the different models, reject misspecified ones and retain the ones that are acceptable and parsimonious (Hu \& Bentler, 1998), we computed the goodness-of-fit indices (TLI, CFI, RMSEA, and AIC) and the path coefficients of our proposed theoretical frameworks using Cheung's (2014) recommended procedure. TLI measures parsimony of the model; CFI measures relative fit; RMSEA index measures absolute fit. Models with RMSEA values less than 0.05 , and CFI and TLI of at least 0.90 indicate a very good fit with the data (Hu \& Bentler, 1998; 1999). We used AIC (Akaike Information Criterion) to select a model balancing between fit and complexity. A lower value of AIC indicates a higher level of parsimony and fit.

We deployed the Weighted Least Squares (WLS) or Asymptotically Distribution-Free (ADF) estimation method for our estimations. We should note that when we use the covariancebased SEM methods such as WLS, goodness-of-fit indices (e.g. TLI) may not be as good as other

${ }^{13} I^{2}=\frac{\hat{\tau}^{2}}{\hat{\tau}^{2}+\hat{\sigma}^{2}} \cdot \hat{\tau}$ and $\hat{\sigma}^{2}$ are the estimated between-study and within-study variance (sampling error) respectively. 
covariance-based SEM methods such as maximum likelihood (Cheung \& Chan, 2005). In other words, the lower values of goodness-of-fit indices do not indicate an inferior fit of the model.

\section{Comparison of View 1 (original) and View 2 (customized): Trust Commitment Models}

The fit indices show that models in which conflict acts as a mediator exhibits a very good fit to the related meta-analytic data (i.e., original Trust-Commitment model: TLI $=.722$; CFI $=.926 ;$ RMSEA $=.011 ;$ Customized model: TLI $=.899 ; \mathrm{CFI}=.980 ; \mathrm{RMSEA}=.007)$. The RMSEA value of customized model is less than the customized models' RMSEA value. Moreover, values of CFI and TLI indices of the customized model are greater than that of the original model. Furthermore, AIC values show that the customized model is a better model in terms of the balance between fit and complexity because AIC of the customized model (.061) is less than that of the original model. (4.790).

\section{Comparison of View 1 (original) and View 2 (customized): Interdependence Models}

Our comparison of the Interdependence frameworks (original vs. customized), revealed stronger evidence for the latter. We found poor fit for original model (i.e., TLI = -.436; CFI = .138 ; RMSEA $=.024$ ) while customized models in which conflict acts as a mediator, exhibit good fit. To control for different types of mediation, we test two customized models here: (i) In the first, conflict fully mediates the effect of interdependence on the outcome variables while, (ii) in the second, conflict partially mediates the effect of interdependence on outcome variables. The fit indices for the first model are: TLI $=.820 ; \mathrm{CFI}=.928$; RMSEA $=.009$. The fit indices of the second model are: $\mathrm{TLI}=.877 ; \mathrm{CFI}=.959 ; \mathrm{RMSEA}=.007$. The lower value of RMSEA and greater values of CFI and TLI indicate that both customized models outperform the original Interdependence model. Furthermore, AIC values show that the second customized model (AIC $=-0.130$, a smaller number) is a better model that the first one $(\mathrm{AIC}=2.543)$ in terms of the balance between fit and complexity. The Chi-Square difference test results also provide support for better fit of the second customized model in which conflict partially mediates the effect of interdependence on exchange outcomes $(\Delta \chi=5.71, \Delta \mathrm{df}=2, \mathrm{p}=.06)$.

\section{Interrelationships: Conflict, Performance, Trust, Commitment, Satisfaction, Interdependence}

We computed path coefficients and their significance levels for all models. We report the results of path analysis using WLS estimation method in Table 4. Since our motivation here is to estimate the aggregate relationships found in existing studies, we are agnostic to any specific directional hypotheses in our investigations of the inter construct relationships. That said, we report the canonical directional hypotheses of the different theoretical perspectives in Table 4.

The results show that conflict mediates the relationship between trust-commitment and exchange outcomes in the customized Trust-Commitment model. In both original and customized Trust-Commitment models, trust and commitment reduce conflict as we expected. For trust, the coefficients for the two models are $\beta=-.068$ and -.067 , respectively $(\mathrm{p}<.01)$; while for commitment the coefficients are $\beta=-.037$ and -.037 , respectively $(\mathrm{p}<.01)$. In the customized model of the Trust-Commitment, conflict has negative effects on performance $(\beta=-.101, p<.01)$ and satisfaction $(\beta=-.202, p<.01)$, respectively. Furthermore, Interdependence magnitude has a non-significant positive effect on trust $(\beta=.009$, not significant), which in turn has a significant positive effect on commitment $(\beta=.061, \mathrm{p}<.01)$. Moreover, interdependence has a significant and positive effect on level of commitment $(\beta=.008, \mathrm{p}<.01)$ in both models of the TrustCommitment. 
<Insert Table 4 here>

The results of both original and customized Interdependence models (recall that we have two customized models here) show that interdependence reduces level of conflict. The coefficient for the original model is $\beta=-.011$, while the coefficients for the full and partial mediation models are $\beta=-.018$ and -.009 respectively. However, none of the effects are statistically significant. More specifically, as earlier, the model in which conflict partially mediates the effect of interdependence on exchange outcomes exhibits better fit than the model in which conflict fully mediates the effect (based on fit indices, AIC value, and Chi-Square different test results). In both customized models of Interdependence, conflict has a negative and significant effect on performance and satisfaction. For performance the coefficients are $\beta=-.108$ and -.110 $(\mathrm{p}<.01)$ for the full and partial mediation models respectively; while for satisfaction the coefficients are $\beta=-.215$ and -.215 ( $\mathrm{p}<.01$ ), respectively. So, for both Trust-Commitment and Interdependence frameworks, the conflict - performance link is negative and significant. Increase in level of conflict leads to decrease in level of performance and satisfaction.

Both the results of pairwise correlation analysis and path analysis show that overall effect size for conflict and performance relationship is negative and significant. We also found that conflict is negatively correlated with trust, commitment, and satisfaction in all models. The direction of relationships among trust, commitment, and satisfaction also are consistent with the literature (Anderson \& Weitz, 1992; Hibbard et al., 2001; Kumar et al., 1995; Morgan \& Hunt, 1994). Trust significantly affects commitment in all tested models, and this result agrees with the literature (Morgan \& Hunt, 1994). Conflict is negatively correlated with interdependence based on our pairwise correlation analysis. The result of path analysis shows that interdependence does affect conflict. However, this effect is not significant in any model. This result is in agreement with previous studies that show that there is a negative relationship between conflict and interdependence magnitude (Frazier \& Rody, 1991; Kumar et al., 1995).

In sum, regardless of the perspectives in use, results of path analysis compellingly support the mediation role of conflict which is consistent with the second view on conflict.

\section{DISCUSSION}

Channel conflict is one of the most consequential business concerns and by extension, one of the more popular constructs studied in the business marketing literature. A literature search shows that the construct "channel conflict" has been used in more than 100 studies since 1960. Our paper addresses two important issues relevant to this literature. Despite the extensive body of research, no study seems to have explicitly addressed the two competing views that dominate how the role of conflict is conceptualized in channel processes. Extant research seems to study the two views only partially and in isolation of each other. As such, despite the plethora of empirical evidence, it is not clear if the aggregate evidence is more in comportment with one or the other view. This is an important concern, for the differences in the manner in which conflict is conceptualized, in turn, naturally lead to different management approach. Given significant resources are often directly or indirectly allocated towards conflict management, ineffective allocations can have non-trivial negative economic consequences for the channel.

The second issue of concern here is that the empirical evidence on the relationship between conflict and performance in channels is often contradictory. As such, the nature of the aggregate archived evidence is unclear.

In this study, we attempt to address these limitations in several ways. First, we compare the two competing views of conflict on three managerially driven themes: channel objective, 
conflict characteristics, and managerial approach towards conflict management; We then conduct an exhaustive meta-analysis of all relevant research papers in the domain that were available. We adopt a research design which allows us to synthesize different perspectives in the literature and analyze the empirical findings for comparative purposes. Our design allows us to investigate the aggregate empirical evidence of the conflict-performance link, as well as the inter-relationships between these and other important interfirm constructs, such as satisfaction, trust, commitment, and interdependence.

Empirically, we compare two competing views on channel conflict by using a two-stage meta-analytic structural equation modeling (TSSEM) technique. We adopt the widely used TrustCommitment and Interdependence frameworks as rival theoretical explanations to tie in the various variables in our study. We then used the Rosenberg and Stern's (1971) intrachannel conflict model to synthesize the two theoretical frameworks. This approach allows us to compare and contrast the two competing views of conflict. Our results suggest, models with conflict as a mediator (View 2) offer a better fit to explain the role of conflict in channel processes, outperforming models in which conflict is considered as the outcome (View 1). Therefore, in balance, the aggregate empirical evidence leans towards View 2.

To investigate the aggregate empirical evidence on the channel conflict-performance link, we examine the pairwise correlations between conflict and performance. We also undertake a similar analysis for other key channel variables. These correlations were gleaned from an exhaustive array of existing research studies using standard meta-analytic techniques. The results of our analyses show that the different correlations for the conflict - performance links were negative and significant, pointing to the wisdom of addressing channel conflict seriously.

We then extend this analysis to investigate the role of channel conflict within the broader nomological network of key channel variables. In particular, we use the TSSEM technique to investigate the inter-relations between conflict, performance, satisfaction, trust, commitment and interdependence. These results largely support the findings from the correlation analyses and offer a detailed look at the aggregate empirical evidence of the inter-relationships between these variables. In particular, the Trust-Commitment theoretical framework seems to perform better at explaining the empirically observed inter-relations between the various variables, compared to the Interdependence theoretical framework.

In practice, managers would find little reason to isolate channel conflict from considerations of channel performance (Pearson \& Monoky, 1976). To that end, the results of our meta-analysis help us to uncover the aggregate evidence linking conflict and performance. In assessing the significance of this, it is important to note that our results necessarily depend on existing empirical studies and thus our research design does not allow us to test new relationships or hypotheses. However, our detailed analysis of the current literature also reveals directions for future research engagement in the domain. In particular, we feel there is one that offers opportunities for significant contributions to the literature.

This pertains to the question of how to manage conflict to achieve a high level of efficiency and performance in channels Despite the significant volume of work in channels, it is an understatement to say that we are yet to map a significant part of the conditions under which conflict impacts efficiency or performance, be it negatively or positively. In particular, we still know little about the conditions under which conflict can be beneficial. With the ongoing changes in the technology environment, multi-channel transactions, technology enabled abilities to monitor, measure, and encourage cooperation and competition among channels (e.g. sales contests) as well as industry trends as dis- and re-intermediation, we are in an age where channel 
conflict has acquired new dimensions. This calls for expanding the frameworks we use to gain insights, generate predictions and design managerial toolkits. We point to two potential frameworks below.

\section{Dynamic Capabilities}

The literature on dynamic capability of firms (cf. Barreto, 2010; Morgan et al., 2009) offers a useful starting point for such expanded framework. This perspective derives from the Resource-Based View (RBV) (Barney, 1991) and the related marketing capability (e.g. Dutta et al., 1999) literature. To the extent conflict and performance are linked in channels, understanding, identifying and developing conflict resolution capabilities in an ongoing basis, are important for marketing channel systems. Failure to do so may invite relationship breakdowns such as litigation that are costly and damaging to brand reputations. Heterogeneity among channels in such capabilities could, in part, determine why some channels avoid such breakdowns, why some firms are better able to manage such breakdowns when faced with them, as well as why the conflict-performance link is positive in some circumstances. When firms move from conflict resolution techniques that focus on conflict reduction to joint performance enhancing and win-win designs, they may experience an increase in performance (Koza \& Dant, 2007). However, the firm's ability to do this would depend on the capabilities they have developed. For example, firms develop bargaining and problem-solving abilities by piecemeal learning through interactions with channel members over the years. This ability to learn from past conflict and adapt to new situations would be facilitated by routines, systems and processes that could serve as a dynamic capability of the firm. We feel this is an area that is particularly ripe for exploration.

\section{Governance Value Analysis}

Investigating conflict management as a strategic capability also calls for understanding how resources are to be deployed to develop such capabilities. While we find governanceoriented approaches, prevalent in View 1 may only be second best to reduce conflict and enhance channel performance, our results nevertheless indicate relational approaches need to be complemented by formal governance mechanisms. So, future research tying in strategic resource allocation with efficiency oriented governance design, seem to be particularly promising. A possible direction for this is the Governance Value Analysis (GVA) framework suggested by Ghosh and John $(1999,2012)$. Their framework sheds lights on the specific trade-offs that firm must make between unique resources and capabilities of the firm, its positioning, transaction attributes, and governance structure.

To conclude, we make four major contributions to the channels conflict literature. First, we conduct a comprehensive meta-analysis of available empirical evidence on the role of conflict in channel outcomes, both financial and relational. To do this, we synthesize empirical evidence from a diverse array of papers. Second, in the process we bring conceptual clarity to two competing views of conflict and identify their empirical significance. We find that current theoretical frameworks can better explain inter-firm relationship when conflict is seen as a mediator. Third, we establish some key empirical generalizations. Our results show that conflict and channel performance are negatively linked and that empirical evidence in support of the Trust-Commitment theoretical framework outperforms the Interdependence framework in explaining the relationships among key channel constructs. Last but not the least, to the best of our knowledge, our paper is among the first to use the two-stage meta-analytic structural equation 
modeling (TSSEM) technique in marketing. This provides more accurate estimates than other techniques in vogue.

\section{MANAGERIAL IMPLICATIONS}

The results of this meta-analysis hold important lessons for managers. Managing channel conflict is a challenging task for four main reasons. First, discerning the marginal effect of channel conflict on channel performance itself is a major challenge. Second, identifying the key variables that impact the outcomes is not always intuitive. Third, the nature of conflict itself is often a moving target spanning the range from a potential for conflict to explicit manifestation. Last but not the least, any efforts at managing such conflicts involve allocation of significant managerial and monetary resources that need to be justified from an efficiency perspective.

The somewhat clear direct implication of our results is that conflict does impact channel performance; and that such impact appears to be negative for the most part. This certainly calls for greater managerial attention to channel conflict, including the task of carefully calibrating the potential impact of channel conflict on the key performance indicators at stake. However, where is such effort better targeted to? Our results seem to re-vindicate two key aspects. The first is to identify the nature of conflict. When conflict manifests in behavioral outcomes (explicit disagreements, non-cooperation, litigation, etc.) the path forward is relatively clear in terms of selecting an appropriate conflict resolution mechanism. However, greater diligence is called for when conflict is not yet manifest but is engendered in the nature of the processes adopted by the channel partners themselves. This calls for a high level of managerial engagement and sensitivity. The second important aspect is to acknowledge the key role of relationship marketing variables, especially that of trust and commitment. While our results cannot offer any new guidance to how such outcomes might be achieved, we nevertheless, highlight the merits of looking upon conflict management as a process, with a retrospective, piecemeal learning approach to problem-solving.

However, managers will be well served to interpret our results in perspective. Our results do not suggest that a forward looking perspective will not yield the channel any rewards. Much to the contrary, our results actually show how forward-looking perspectives also lead to good fit of the derived models. There is a lot of merit in being able to anticipate and act, in particular, to scan the environment and business situation to identify potential sources of conflict. In reality, it is a combination of the retrospective and forward-looking strategies that is likely to be the key to achieving the best channel outcomes. But what form should this combined strategy take?

In highlighting the mediating role of conflict, our results suggest that principals in the channels need to take a leading role in managing conflict. In a principal-agent framework, the principal is tasked with setting forth the channel design. It seems natural then that they also are tasked with the job of deploying the appropriate conflict resolution techniques. That by itself is not surprising of course. However, when we look upon this task through the lens of appropriate conflict resolution techniques, our results suggest that the principals' key focus should be on designs and interventions that lead to greater trust and commitment between them and their channel partners. While this can take multiple forms, perhaps a zero-sum approach will not yield the right dividends to the efforts. In particular, efforts such as problem-solving and persuasion that lead to win-win outcomes for all participating channel members (Koza \& Dant, 2007) is likely to be more effective. Furthermore, in approaching this task, principals will be well served to understand that this is, in essence, a collaborative task and encourage their channel partners (agents, in the principal-agent paradigm) also to contribute meaningfully. 
Scholars have long held that conflict resolution plays an important role in managing interfirm relationships (Lusch, 1976; Rosenberg \& Stern, 1970). Findings from this study have practical implications for channel members who are involved in managing and resolving channel conflict. Channel managers should not only design governance mechanisms that prevent channel conflict but should also actively sense and respond to what happens in the channel. If channel conflict is managed as an on-going process, managers can better direct their efforts to increase efficiency in the whole channel.

\section{LIMITATIONS AND FUTURE RESEARCH}

As with any study, ours has some limitations. While we have strived for rigor in our paper, it sometimes came at the cost of completeness. We do not believe this incompleteness is a significant challenge to our key findings, but we do acknowledge that we may have been able to capture more nuances in our results with the benefit of more data. First, the number of constructs that are included in our model is limited because we could not find enough correlation coefficients for important inter-firm constructs such as opportunism and interdependence asymmetry. Moreover, the different sources of conflict such as goal incompatibility, drive for autonomy, and miscommunication could act as antecedents of conflict, but we did not include them in our model due to lack of enough correlation coefficients. The presence and effects of missed constructs could better explain the effect and role of conflict in channel setting. Second, we could not test the inverted-U shape relationship that is proposed by Rosenbloom (1973). With very few published studies on this, it remains one of the key areas for future research in marketing channels. In fact, to the best of our knowledge, there exist only two published papers in marketing that empirically tested the inverted U-shape relationship between conflict and performance (Duarte \& Davies, 2003; Lusch, 1976). Third, the observed heterogeneity among relationships between the channel constructs, point to the need for more investigations into possible factors that might affect the conflict - performance link. These observations reflect the general paucity of research into factors that moderate the conflict-performance link.

Finally, there is the issue of measurement. We have focused mostly on financial measures in our study but expanding the set to other measures would help us generate a broader understanding of the domain. In fact, the use of different performance indicators such as perceptual vs. grounded and efficiency vs. effectiveness ( $c f$. Duarte \& Davies, 2003) could affect the sign and size of the effects, building on our results and spurring further investigations. 


\section{REFERENCES}

Agrawal, D., \& Lal, R. (1995). Contractual arrangements in franchising: An empirical investigation. Journal of Marketing Research, 32(2), 213-221.

Anderson, E., \& Weitz, B. (1992). The use of pledges to build and sustain commitment in distribution channels. Journal of Marketing Research, 18-34.

Antia, K. D., Zheng, X., \& Frazier, G. L. (2013). Conflict management and outcomes in franchise relationships: the role of regulation. Journal of Marketing Research, 50(5), 577-589.

Assael, H. (1969). Constructive role of interorganizational conflict. Administrative Science Quarterly, 573-582.

Balliet, D., \& Van Lange, P. A. (2013). Trust, conflict, and cooperation: A metaanalysis. Psychological Bulletin, 139(5), 1090.

Barney, J. (1991). Firm resources and sustained competitive advantage. Journal of Management, 17(1), 99-120.

Barreto, I. (2010). Dynamic capabilities: A review of past research and an agenda for the future. Journal of Management, 36(1), 256-280.

Bhardwaj, P., \& Balasubramanian, S. (2005). Managing channel profits: The role of managerial incentives. Quantitative Marketing \& Economics, 3(3), 247-279.

Boker, S., Neale, M., Maes, H., Wilde, M., Spiegel, M., Brick, T., ... \& Fox, J. (2011). OpenMx: An open source extended structural equation modeling framework. Psychometrika, 76(2), 306-317.

Bradford, K. D., Stringfellow, A., \& Weitz, B. A. (2004). Managing conflict to improve the effectiveness of retail networks. Journal of Retailing, 80(3), 181-195.

Brown, J. R. (1980). More on the channel conflict-performance relationship. Theoretical Developments in Marketing, 328-345.

Brown, J. R., Cobb, A. T., \& Lusch, R. F. (2006). The roles played by interorganizational contracts and justice in marketing channel relationships. Journal of Business Research, 59(2), 166-175.

Brown, J. R., Lusch, R. F., \& Muehling, D. D. (1983). Conflict and power-dependence relations in retailer-supplier channels. Journal of Retailing, 59(4), 53-80.

Brown, S. P., \& Peterson, R. A. (1993). Antecedents and consequences of salesperson job satisfaction: Meta-analysis and assessment of causal effects. Journal of Marketing Research, 30, 63-63.

Browne, M. W. (1984). Asymptotically distribution-free methods for the analysis of covariance structures. British Journal of Mathematical and Statistical Psychology, 37(1), 62-83.

Chang, K. H., \& Gotcher, D. F. (2010). Conflict-coordination learning in marketing channel relationships: The distributor view. Industrial Marketing Management, 39(2), 287-297.

Cheung, M. W. L. (2013). metaSEM: An R Package for Meta-Analysis Using Structural Equation Modeling, in, National University of Singapore, Singapore, 1-47.

Cheung, M. W. L. (2014). Fixed- and random-effects meta-analytic structural equation modeling: Examples and analyses in R. Behavior Research Methods, 46, 29-40.

Cheung, M. W. L., \& Chan, W. (2005). Meta-analytic structural equation modeling: A two-stage approach. Psychological Methods, 10(1), 40.

Cheung, M. W. L. \& Chan, W. (2009). A two-stage approach to synthesizing covariance matrices in meta-analytic structural equation modeling, Structural Equation Modeling, 16, 28-53.

Cohen, J. (1988). Statistical Power Analysis for the Behavioral Sciences. Hillsdale, NJ: Lawrence Erlbaum Associates Publishers.

Choi, S. C. (1991). Price competition in a channel structure with a common retailer. Marketing Science, 10(4), 271-296. 
Crosno, J. L., \& Dahlstrom, R. (2010). Examining the nomological network of opportunism: A meta-analysis. Journal of Marketing Channels, 17(3), 177-190.

Dant, R. P., \& Schul, P. L. (1992). Conflict resolution processes in contractual channels of distribution. The Journal of Marketing, 38-54.

Deutsch, M. (1958). Trust and suspicion. Journal of Conflict Resolution, 2, 265-279.

Duarte, M., \& Davies, G. (2003). Testing the conflict-performance assumption in business-tobusiness relationships. Industrial Marketing Management, 32(2), 91-99.

Dutta, S., Narasimhan, O., \& Rajiv, S. (1999). Success in high-technology markets: Is marketing capability critical?. Marketing Science, 18(4), 547-568.

Dwyer, F. R., Schurr, P. H., \& Oh, S. (1987). Developing buyer-seller relationships. The Journal of Marketing, 11-27.

Etgar, M. (1979). Sources and types of intra-channel conflict. Journal of Retailing, 55(1), 61-78.

Frazier, G. L. (1999). Organizing and managing channels of distribution. Journal of the Academy of Marketing Science, 27(2), 226-240.

Frazier, G. L., \& Rody, R. C. (1991). The use of influence strategies in interfirm relationships in industrial product channels. Journal of Marketing, 55(January), 52-69.

Frazier, G. L., Gill, J. D., \& Kale, S. H. (1989). Dealer dependence levels and reciprocal actions in a channel of distribution in a developing country. The Journal of Marketing, 50-69.

Gilliland, D. I., Bello, D. C., \& Gundlach, G. T. (2010). Control-based channel governance and relative dependence. Journal of the Academy of Marketing Science, 38(4), 441-455.

Geyskens, I., Steenkamp, J. B. E., \& Kumar, N. (1998). Generalizations about trust in marketing channel relationships using meta-analysis. International Journal of Research in Marketing, 15(3), 223-248.

Geyskens, I., Steenkamp, J. B. E., \& Kumar, N. (1999). A meta-analysis of satisfaction in marketing channel relationships. Journal of Marketing Research, 223-238.

Geyskens, I., Steenkamp, J. B. E., \& Kumar, N. (2006). Make, buy, or ally: A transaction cost theory meta-analysis. Academy of Management Journal, 49(3), 519-543.

Ghosh, M., \& John, G. (1999). Governance value analysis and marketing strategy. The Journal of Marketing, 131-145.

Ghosh, M., \& John, G. (2012). Progress and prospects for governance value analysis in marketing: when Porter meets Williamson. Cheltenham, UK: Edward Elgar.

Hedges, L. V., \& Olkin, I. (2014). Statistical method for meta-analysis. Academic press.

Hedges L. V., \& Pigott, T. D. (2001). The power of statistical tests in meta-analysis. Psychological Methods, 6(3), 203-217.

Heide, J. B., \& John, G. (1988). The role of dependence balancing in safeguarding transactionspecific assets in conventional channels. Journal of Marketing, 52(1) 20-35.

Hibbard, J. D., Kumar, N., \& Stern, L. W. (2001). Examining the impact of destructive acts in marketing channel relationships. Journal of Marketing Research, 38(1), 45-61.

Higgins, J. \& Thompson, S.G. (2002). Quantifying heterogeneity in a meta- analysis, Statistics in Medicine, 21, 1539-1558.

Hu, L. T., \& Bentler, P. M. (1998). Fit indices in covariance structure modeling: Sensitivity to underparameterized model misspecification. Psychological Methods, 3(4), 424.

Hu, L. T., \& Bentler, P. M. (1999). Cutoff criteria for fit indexes in covariance structure analysis: Conventional criteria versus new alternatives. Structural Equation Modeling: a Multidisciplinary Journal, 6(1), 1-55. 
Hunger, J. D., \& Stern, L. W. (1976). An assessment of the functionality of the superordinate goal in reducing conflict. Academy of Management Journal, 19(4), 591-605.

Hunt, K. A. (1995). The relationship between channel conflict and information processing. Journal of Retailing, 71(4), 417-436.

Hunt, S. D., Ray, N. M., \& Van Wood, R. (1985). Behavioral dimensions of channels of distribution: Review and synthesis. Journal of the Academy of Marketing Science, 13(3), 1-24.

Hunter, J. E. \& Schmidt, F. L. (1990). Methods of meta- analysis: correcting error and bias in research findings. Newbury Park, CA: Sage Publications.

Ingene, C. A., \& Parry, M. E. (1995). Channel coordination when retailers compete. Marketing Science, 14(4), 360-377.

Kim, S. K., \& Hsieh, P. H. (2003). Interdependence and its consequences in distributor-supplier relationships: A distributor perspective through response surface approach. Journal of Marketing Research, 40(1), 101-112.

Koza, K. L., \& Dant, R. P. (2007). Effects of relationship climate, control mechanism, and communications on conflict resolution behavior and performance outcomes. Journal of Retailing, 83(3), 279-296.

Kumar, N., Scheer, L. K., \& Steenkamp, J. B. E. (1995). The effects of perceived interdependence on dealer attitudes. Journal of Marketing Research, 348-356.

Kumar, N., Scheer, L. K., \& Steenkamp, J. B. E. (1998). Interdependence, punitive capability, and the reciprocation of punitive actions in channel relationships. Journal of Marketing Research, 225-235.

Kumar, N., Stern, L. W., \& Achrol, R. S. (1992). Assessing reseller performance from the perspective of the supplier. Journal of Marketing Research, 238-253.

Jap, S. D., \& Ganesan, S. (2000). Control mechanisms and the relationship life cycle: Implications for safeguarding specific investments and developing commitment. Journal of Marketing Research, 37(2), 227-245.

Jeuland, A. P., \& Shugan, S. M. (1983). Managing channel profits. Marketing Science, 2(3), 239272.

John, G., \& Weitz, B. (1988). Forward Integration into distribution: An empirical test of Transaction Cost Analysis. Journal of Law, Economics, and Organization, 4(November), 337-355.

Landis, R. S. (2013). Successfully combining meta-analysis and structural equation modeling: Recommendations and strategies. Journal of Business and Psychology, 28(3), 251-261.

Lengers, J., Dant, R. P., \& Meiseberg, B. (2015). Conflict Dynamics in Interfirm Relationships: An Exploratory Analysis of the Importance of Governance Mechanisms. In Interfirm Networks (pp. 273-297). Springer International Publishing.

Lusch, R. F. (1976). Channel Conflict: Its Impact on retailer operating performance. Journal of Retailing, 52(2), 3-12.

Menon, A., Bharadwaj, S. G., \& Howell, R. (1996). The quality and effectiveness of marketing strategy: Effects of functional and dysfunctional conflict in intraorganizational relationships. Journal of the Academy of Marketing Science, 24(4), 299-313.

Meyers, L. S., Gamst, G., \& Guarino, A. J. (2006). Applied multivariate research: Design and interpretation. Sage Publications.

Mohr, J. J., Fisher, R. J., \& Nevin, J. R. (1996). Collaborative communication in interfirm relationships: moderating effects of integration and control. The Journal of Marketing, 103-115.

Moorman, C., Zaltman, G., \& Deshpande, R. (1992). Relationships between providers and users of market research: The dynamics of trust. Journal of Marketing Research, 29(3), 314-328. 
Morgan, R. M., \& Hunt, S. D. (1994). The commitment-trust theory of relationship marketing. The Journal of Marketing, 20-38.

Morgan, N. A., Vorhies, D. W., \& Mason, C. H. (2009). Market orientation, marketing capabilities, and firm performance. Strategic Management Journal, 30(8), 909-920.

Orwin, R. G. (1983). A fail-safe $\mathrm{N}$ for effect size in meta-analysis. Journal of Educational Statistics, 157-159.

Palmatier, R. W., Dant, R. P., Grewal, D., \& Evans, K. R. (2006). Factors influencing the effectiveness of relationship marketing: a meta-analysis. Journal of Marketing, 70(4), 136-153.

Palmatier, R. W., Dant, R. P., \& Grewal, D. (2007). A comparative longitudinal analysis of theoretical perspectives of interorganizational relationship performance. Journal of Marketing, 71(4), 172-194.

Pearson, M. (1973). The conflict-performance assumption. Journal of Purchasing, 9(1), 57-70.

Pearson, M., \& Monoky, J. E. (1976). The Role of Conflict and Cooperation in Channel Performance, in Marketing: 1776-1976 and Beyond, Educators' Conference Proceedings, Series No. 39, Kenneth L. Bernhardt, ed., Chicago: American Marketing Association, 240-244.

Peterson, R. A., \& Brown, S. P. (2005). On the use of beta coefficients in meta-analysis. Journal of Applied Psychology, 90(1), 175.

Pondy, L. R. (1967). Organizational conflict: Concepts and models. Administrative Science Quarterly, 296-320.

Poppo, L., \& Zenger, T. (2002). Do formal contracts and relational governance function as substitutes or complements?. Strategic Management Journal, 23(8), 707-725.

Reve, T., \& Stern, L. W. (1979). Interorganizational relations in marketing channels. Academy of Management Review, 4(3), 405-416.

Robbins, J. E., Speh, T. W., \& Mayer, M. L. (1982). Retailers Perceptions of Channel Conflict Issues. Journal of Retailing, 58(4), 46-67.

Rosenberg, L. J. (1974). A new approach to distribution conflict management. Business Horizons, 17(5), 67-74.

Rosenberg, L. J., \& Stern, L. W. (1970). Toward the analysis of conflict in distribution channels: A descriptive model. The Journal of Marketing, 40-46.

Rosenberg, L. J., \& Stern, L. W. (1971). Conflict measurement in the distribution channel. Journal of Marketing Research, 8(4), 437-442.

Rosenbloom, B. (1973). Conflict and channel efficiency: some conceptual models for the decisionmaker. Journal of Marketing, 37, 26-30.

Rosenbloom, B. (2007). Multi-channel strategy in business-to-business markets: prospects and problems. Industrial Marketing Management, 36(1), 4-9.

Rosenthal, R. (1979). The file drawer problem and tolerance for null results. Psychological Bulletin, 86(3), 638-41.

Rosenthal, R. (1994). Parametric measures of effect size. In H. Cooper \& L. V. Hedges (Eds.), The handbook of research synthesis, 231-244. New York: Russell Sage Foundation.

Ross Jr, W. T., Anderson, E., \& Weitz, B. (1997). Performance in principal-agent dyads: The causes and consequences of perceived asymmetry of commitment to the relationship. Management Science, 43(5), 680-704.

Ross, R. H., \& Lusch, R. F. (1982). Similarities between conflict and cooperation in the marketing channel. Journal of Business Research, 10(2), 237-250.

Rothstein, H. R., Sutton, A. J., \& Borenstein, M. (2006). Publication bias in meta-analysis: Prevention, assessment, and adjustments. John Wiley \& Sons. 
Samaha, S. A., Palmatier, R. W., \& Dant, R. P. (2011). Poisoning relationships: Perceived unfairness in channels of distribution. Journal of Marketing, 75(3), 99-117.

Scheer, L. K., Miao, C. F., \& Palmatier, R. W. (2014). Dependence and interdependence in marketing relationships: Meta-analytic insights. Journal of the Academy of Marketing Science, 119.

Schermerhorn, J. R. (1975). Determinants of interorganizational cooperation. Academy of Management Journal, 18(4), 846-856.

Sherif, M., Harvey, O. J., White, B. J., Hood, W. R., \& Sherif, C. W. (1961). Intergroup cooperation and conflict: The robbers cave experiment. Norman, OK: University of Oklahoma Book Exchange.

Stern, L. W. (1971). The interorganization management of distribution channels: Prerequisites and prescriptions. New essays in marketing theory. Allyn and Bacon Inc., Boston, 301-314.

Stern, L. W., El-Ansary, A. I., \& Coughlan, A. T. (1996). Marketing channels, (Vol. 5). Upper Saddle River, NJ: Prentice Hall.

Thomas, K. (1976). Conflict and Conflict Management in Handbook of Industrial and Organizational Psychology, Marvin D. Dunnette, ed., Chicago: Rand McNally, 889-935.

Van de Ven, A. H., \& Walker, G. (1984). The dynamics of interorganizational coordination. Administrative Science Quarterly, 598-621.

Verbeke, W., Dietz, B., \& Verwaal, E. (2011). Drivers of sales performance: a contemporary metaanalysis. Have salespeople become knowledge brokers?. Journal of the Academy of Marketing Science, 39(3), 407-428.

Viswesvaran, C., \& Ones, D. S. (1995). Theory testing: Combining psychometric meta- analysis and structural equations modeling. Personnel Psychology, 48(4), 865-885.

Webb, K. L. (2002). Managing channels of distribution in the age of electronic commerce. Industrial Marketing Management, 31(2), 95-102.

Webb, K. L., \& Hogan, J. E. (2002). Hybrid channel conflict: Causes and effects on channel performance. Journal of Business \& Industrial Marketing, 17(5), 338-356.

Wernerfelt, B. (1994). An efficiency criterion for marketing design. Journal of Marketing Research, 462-470.

Williamson, O. E. (1985). The economic institutions of capitalism. New York: Free Press.

Zaheer, A., McEvily, B., \& Perrone, V. (1998). Does trust matter? Exploring the effects of interorganizational and interpersonal trust on performance. Organization Science, 9(2), 141-159.

Zhou, N., Zhuang, G., \& Yip, L. S. C. (2007). Perceptual difference of dependence and its impact on conflict in marketing channels in China: An empirical study with two-sided data. Industrial Marketing Management, 36(3), 309-321. 


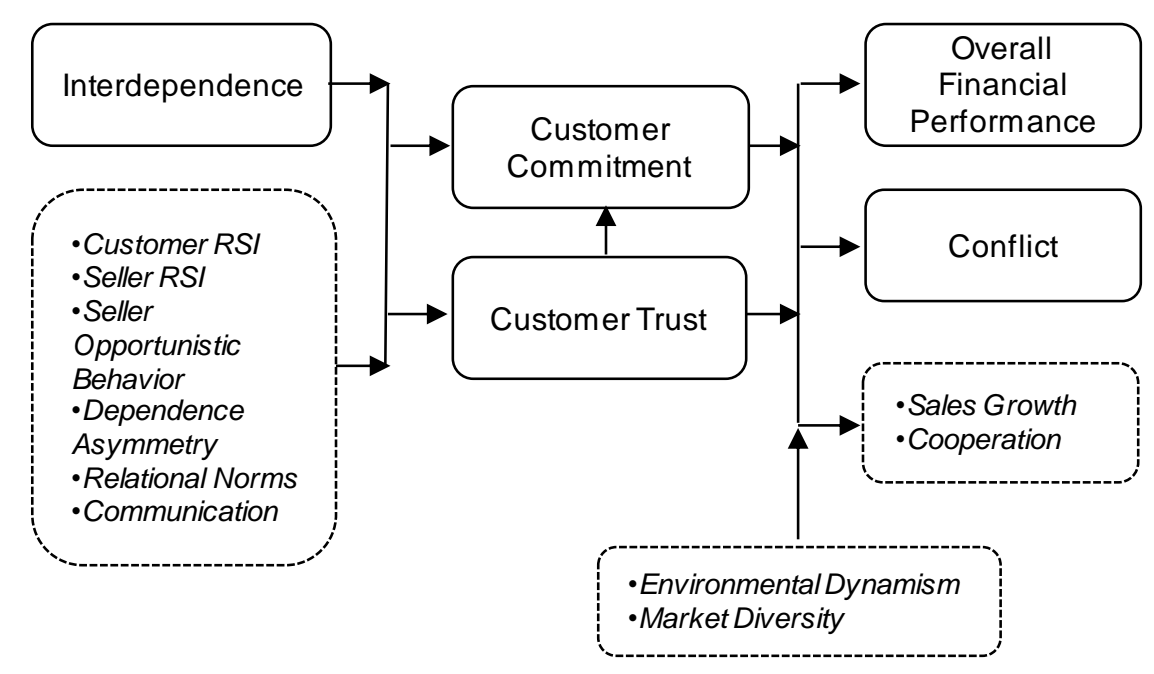

(a) Original Trust-Commitment perspective

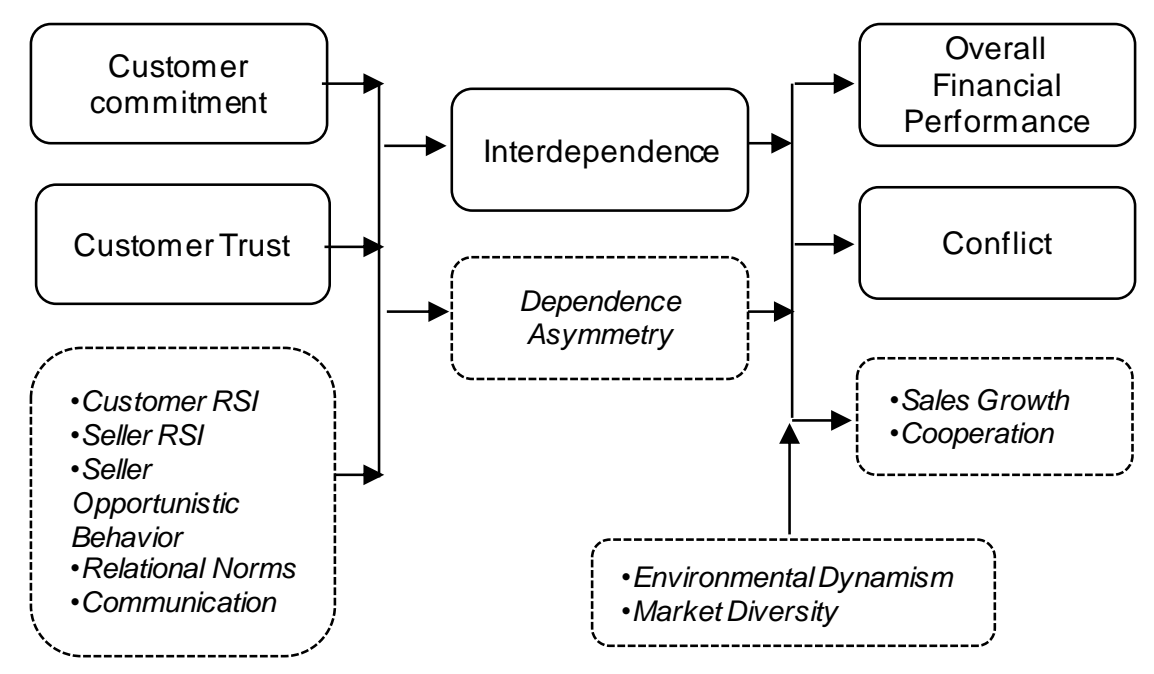

(b) Original Interdependence perspective

\section{Figure 1: View 1 of Channel Conflict -Trust-Commitment and Interdependence perspectives}

(Notes: Dashed constructs are deleted from model because of lack of enough data; RSI = Relationship-Specific Investments) 


\begin{tabular}{|c|c|c|c|c|}
\hline Antecedents & Structural and & Mediators & & Outcomes \\
\hline acof & factors & & to conflict & Outcomes \\
\hline conflict & & Levetor couratal & & behavioral) \\
\hline
\end{tabular}

(a) View 2 of Channel Conflict - The Intra-channel Conflict Process (Rosenberg \& Stern, 1971, p. 438)

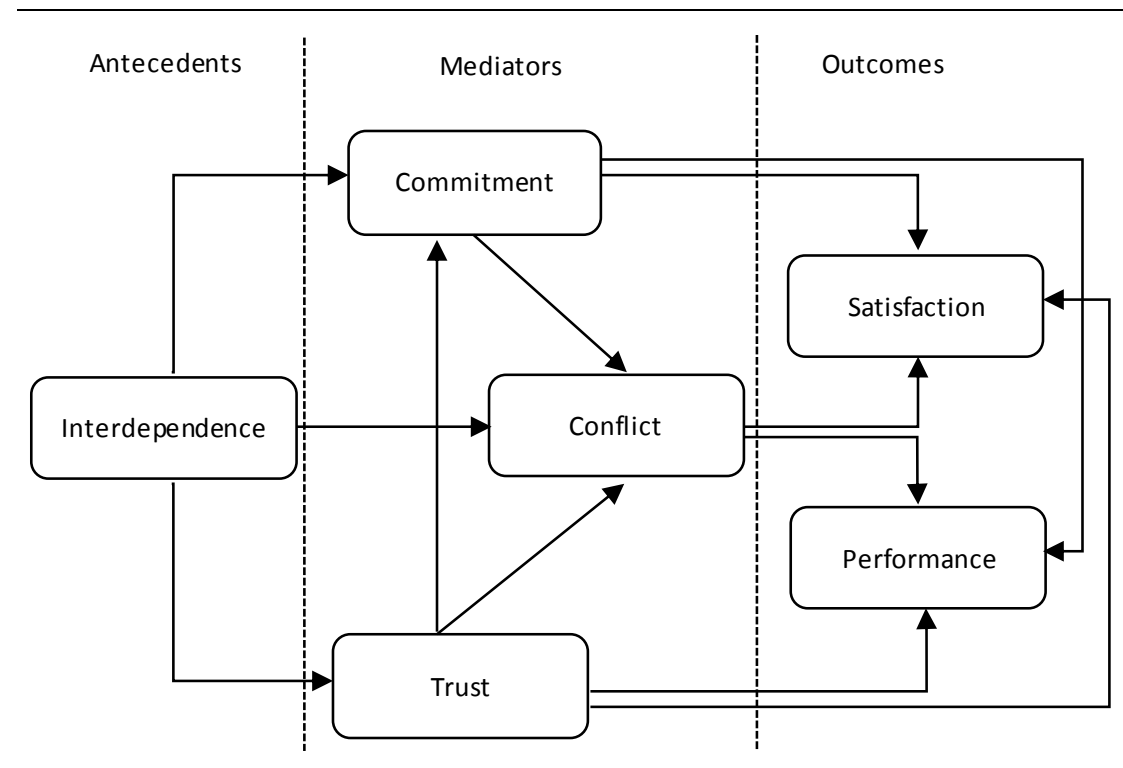

(b) Customized model - synthesizing Trust-Commitment perspective (View 1) into the Intra-Channel perspective (View 2)

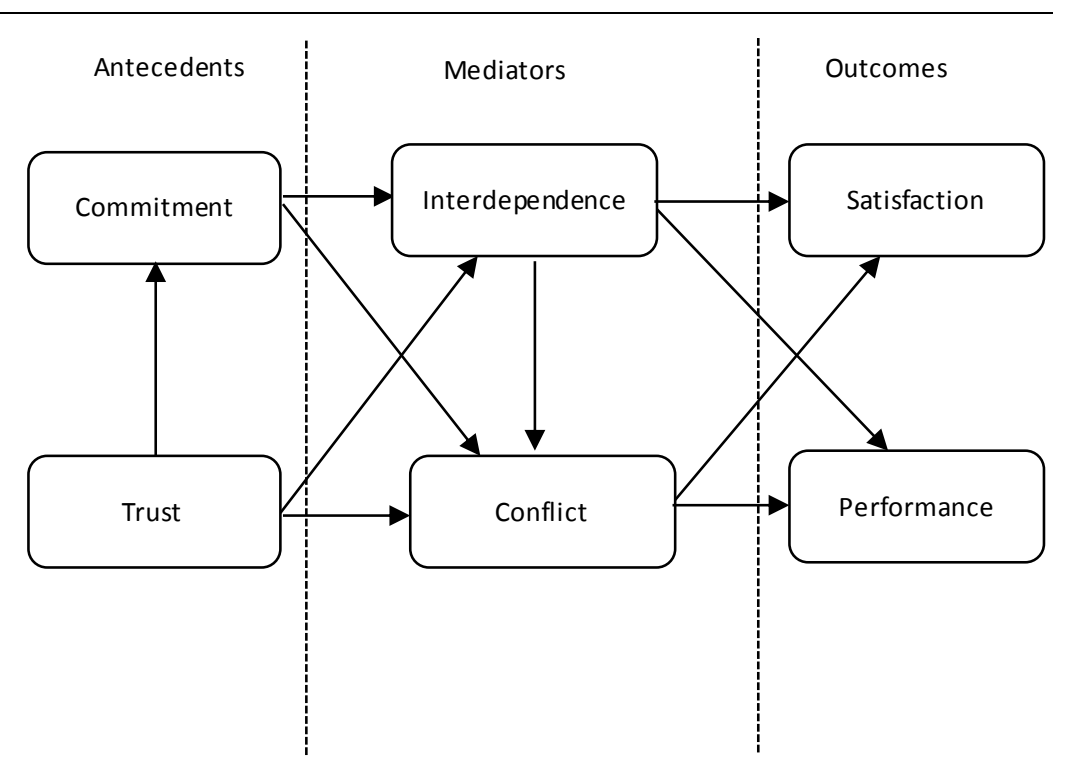

(c) Customized model - synthesizing Interdependence perspective View 1) into the Intra-Channel perspective (View 2 (Conflict, as well as interdependence, mediates the relationship between antecedents and consequence of channel)

Figure 2: View 2 of Channel Conflict - the original Intra-Channel and the estimated customized models 
Table 1: A Comparison of the two views of Channel Conflict

\begin{tabular}{|c|c|c|}
\hline Comparison & View 1 & View 2 \\
\hline $\begin{array}{l}\text { Channel } \\
\text { Objectives }\end{array}$ & $\begin{array}{l}\text { Minimizing conflict; Design- and governance- } \\
\text { oriented; Focus on own performance } \\
\text { maximization via reducing conflict; Zero-sum } \\
\text { ok. }\end{array}$ & $\begin{array}{l}\text { Maximizing joint performance; Sense and } \\
\text { respond approach; Win-win outcome is the } \\
\text { focus. }\end{array}$ \\
\hline Sample Papers & $\begin{array}{l}\text { Assael 1968; Hunger and Stern 1976; Reve } \\
\text { and Stern 1979; Stern, Sternthal, and Craig } \\
\text { 1973; Thompson } 1960 .\end{array}$ & $\begin{array}{l}\text { Anderson and Narus 1990; Frazier, Gill, and } \\
\text { Kale 1989; Guiltinan, Rejab, and Rodgers } \\
\text { 1980; Hunt 1995; Litterer 1966; Mallen 1967; } \\
\text { Rose and Shoham 2004; Rosenberg } 1974 .\end{array}$ \\
\hline $\begin{array}{l}\text { Conflict } \\
\text { Characteristics }\end{array}$ & $\begin{array}{l}\text { Negative outcome; dysfunctional; conflict is } \\
\text { the lack of coordination; Focused on manifest } \\
\text { conflict; Conflict is viewed as partially static } \\
\text { phenomenon. }\end{array}$ & $\begin{array}{l}\text { Functional and dysfunctional; Conflict and } \\
\text { cooperation are distinct constructs; Conflict is } \\
\text { viewed as explicit and mostly dynamic } \\
\text { phenomenon. }\end{array}$ \\
\hline Sample Papers & $\begin{array}{l}\text { Brown and Day 1981; Brown and Frazier } \\
\text { 1978; Dixon and Layton 1971; Geyskens, } \\
\text { Steenkamp, and Kumar 1999; Lee, 2001; } \\
\text { Mohr, Fisher, and Nevin, 1996; Pearson and } \\
\text { Monoky 1976; Pruden 1969; Sherif } 1958 .\end{array}$ & $\begin{array}{l}\text { Assael 1969; Cadotte and Stern 1979; Cronin } \\
\text { and Morris 1989; Eliashberg and Mitchie } \\
\text { 1984; Etgar 1979; Hunger and Stern 1976; } \\
\text { Koza and Dant 2007; Menon, Bharadwaj, and } \\
\text { Howell, 1996; Pondy 1967; Rawwas, Vitell, } \\
\text { and Barnes 1997; Reve and Stern 1979; } \\
\text { Rosenberg and Stern 1971; Rosenbloom } \\
\text { 1973; Skinner, Gassenheimer, and Kelley, } \\
\text { 1992. }\end{array}$ \\
\hline $\begin{array}{l}\text { Managerial } \\
\text { Approach }\end{array}$ & $\begin{array}{l}\text { No real-time intervention; Channel design will } \\
\text { prevent conflict; Forward-looking orientation. }\end{array}$ & $\begin{array}{l}\text { Use of problem solving and persuasion; Real- } \\
\text { time intervention is allowed; Retrospective } \\
\text { oriented; Based on learning and evolution. }\end{array}$ \\
\hline Sample Papers & $\begin{array}{l}\text { Assael 1968; Ghosh and John 2012; Hunger } \\
\text { and Stern 1976; Robbins, Speh, and Meyer } \\
\text { 1982; Rosenberg 1974; Thompson } 1960 .\end{array}$ & $\begin{array}{l}\text { Angelmar and Stern 1978; Chang and } \\
\text { Gotcher, 2010; Hunt 1995; Lengers, Dant, and } \\
\text { Meiseberg, 2015; Rawwas, Vitell, and Barnes } \\
\text { 1997; Roering 1977; Rosenberg 1974; Walker } \\
\text { 1971. }\end{array}$ \\
\hline
\end{tabular}

(Note: To save space and for convenience, we report all the papers cited here, in Appendix B) 
Table 2: Descriptive statistics and results of pairwise analyses

\begin{tabular}{|c|c|c|c|c|c|c|c|c|c|c|c|c|}
\hline Construct 1 & Construct 2 & $\begin{array}{r}\text { Simple } \\
\text { average } \\
r\end{array}$ & $\begin{array}{r}\text { Average } r \\
\text { adjusted } \\
\text { for } \\
\text { reliability }\end{array}$ & $Z$ & $\begin{array}{r}\text { Sample } \\
\text { weighted } Z \\
\text { adjusted for } \\
\text { reliability } \\
\end{array}$ & $\begin{array}{r}\text { Transforme } \\
\text { d back } r\end{array}$ & $\begin{array}{r}95 \% \\
\text { CI } \\
\text { LB }\end{array}$ & $\begin{array}{r}95 \% \\
\text { CI } \\
\text { UB }\end{array}$ & $\begin{array}{r}\text { Total } \\
\text { number } \\
\text { of raw } \\
\text { effects } \\
\end{array}$ & $\begin{array}{r}\text { Total } \\
N\end{array}$ & $\begin{array}{r}\text { File } \\
\text { drawer } \\
N \text { (two- } \\
\text { tailed) } \\
\end{array}$ & $\begin{array}{r}Q \text {-statistic of } \\
\text { homogeneity } \\
\text { (df) }\end{array}$ \\
\hline Conflict & Performance & -.146 & -.169 & -.197 & $-.403^{* *}$ & -.382 & -.425 & -.380 & 53 & 10,297 & 757 & $3,229.731(52)^{* *}$ \\
\hline Conflict & Satisfaction & -.367 & -.442 & -.539 & $-.694^{* *}$ & -.613 & -.718 & -.670 & 54 & 9,897 & 1,445 & $1,479.294(53)^{* *}$ \\
\hline Conflict & Interdependence & -.089 & -.101 & -.107 & $-.114^{* *}$ & -.113 & -.144 & -.083 & 13 & 5,856 & 46 & $97.911(12)^{* *}$ \\
\hline Conflict & Trust & -.369 & -.446 & -.562 & $-.558^{* *}$ & -.506 & -.587 & -.529 & 22 & 6,132 & 469 & $1259.886(21)^{* *}$ \\
\hline Conflict & Commitment & -.239 & -.310 & -.365 & $-.267^{* *}$ & -.261 & -.306 & -.227 & 13 & 3,795 & 126 & $739.730(12)^{* *}$ \\
\hline Performance & Satisfaction & .318 & .380 & .541 & $1.190^{* *}$ & .831 & 1.150 & 1.231 & 15 & 3,508 & 699 & $2,264.412(14)^{* *}$ \\
\hline Performance & Interdependence & .172 & .199 & .213 & $.202^{* *}$ & .199 & .168 & .236 & 9 & 4,628 & 64 & $218.513(8)^{* *}$ \\
\hline Performance & Trust & .387 & .473 & .534 & $.432^{* *}$ & .407 & .376 & .487 & 8 & 1,752 & 130 & $68.909(7)^{* *}$ \\
\hline Performance & Commitment & .292 & .353 & .523 & $.651^{* *}$ & .573 & .597 & .706 & 6 & 1,766 & 150 & $736.823(5)^{* *}$ \\
\hline Satisfaction & Interdependence & .254 & .296 & .318 & $.338^{* *}$ & .326 & .271 & .406 & 4 & 1,283 & 48 & $40.495(3)^{* *}$ \\
\hline Satisfaction & Trust & .583 & .704 & .865 & $.940^{* *}$ & .735 & .898 & .981 & 11 & 3,191 & 402 & $182.182(10)^{* *}$ \\
\hline Satisfaction & Commitment & .372 & .522 & .613 & $.640^{* *}$ & .565 & .569 & .711 & 6 & 1,472 & 148 & $41.317(5)^{* *}$ \\
\hline Interdependence & Trust & .119 & .143 & .147 & $.191^{* *}$ & .189 & .140 & .243 & 7 & 2,136 & 46 & $23.975(6)^{* * *}$ \\
\hline Interdependence & Commitment & .194 & .206 & .212 & $.200^{* *}$ & .198 & .151 & .249 & 5 & 1,895 & 35 & $13.658(4)^{* *}$ \\
\hline Trust & Commitment & .605 & .730 & .976 & $.945^{* *}$ & .738 & .904 & .986 & 9 & 3,207 & 285 & $163.480(8)^{* * *}$ \\
\hline
\end{tabular}

** Sig at $\mathrm{p}<.05$ 
Table 3: The $I^{2}$ heterogeneity indices for correlation coefficients among the factors

\begin{tabular}{|c|c|c|c|c|c|c|}
\hline & Performance & Satisfaction & Trust & Commitment & Conflict & Interdependence \\
\hline Performance & 0.000 & & & & & \\
\hline Satisfaction & .844 & 0.000 & & & & \\
\hline Trust & 0.636 & 0.674 & 0.000 & & & \\
\hline Commitment & 0.916 & 0.578 & 0.883 & 0.000 & & \\
\hline Conflict & 0.548 & 0.964 & 0.610 & 0.896 & 0.000 & \\
\hline Interdependence & 0.916 & 0.142 & 0.774 & 0.089 & 0.417 & 0.000 \\
\hline
\end{tabular}


Table 4: Construct inter-relationships: Path coefficients

\begin{tabular}{|c|c|c|c|c|c|c|c|c|}
\hline \multirow{2}{*}{$\begin{array}{l}\text { Construct } 1 \rightarrow \\
\text { Construct2 }\end{array}$} & \multicolumn{3}{|c|}{ Canonical Hypotheses $^{\#}$} & \multirow{2}{*}{$\begin{array}{r}\text { Model 1 } \\
\text { (original } \\
\text { Trust- } \\
\text { Commit.) }\end{array}$} & \multirow{2}{*}{ 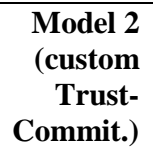 } & \multirow{2}{*}{$\begin{array}{r}\text { Model 3 } \\
\text { (original } \\
\text { Interdep.) }\end{array}$} & \multirow{2}{*}{$\begin{array}{r}\begin{array}{r}\text { Model } 4 \\
\text { (custom }\end{array} \\
\text { Interdep 1.) } \\
\text { Full mediation } \\
\end{array}$} & \multirow{2}{*}{$\begin{array}{r}\begin{array}{r}\text { Model 5 } \\
\text { (custom }\end{array} \\
\text { Interdep. 2) } \\
\text { Part mediation } \\
\end{array}$} \\
\hline & Trust-Commit. & Interdep. & Intra-channel & & & & & \\
\hline $\begin{array}{l}\text { Conflict } \rightarrow \\
\text { Performance }\end{array}$ & & & $-/+$ & - & $-0.101^{* * *}$ & - & $-.1082^{* * *}$ & $-.110^{* * *}$ \\
\hline $\begin{array}{l}\text { Conflict } \rightarrow \\
\text { Satisfaction } \\
\end{array}$ & & & - & - & $-0.202^{* *}$ & - & $-.215^{* *}$ & $-.215^{* *}$ \\
\hline $\begin{array}{l}\text { Interdependence } \rightarrow \\
\text { Conflict }\end{array}$ & & $-/+$ & - & - & -0.018 & -0.011 & -0.018 & -0.009 \\
\hline $\begin{array}{l}\text { Trust } \rightarrow \\
\text { Conflict } \\
\end{array}$ & - & & - & $-.068^{* *}$ & $-0.067^{* *}$ & - & $-.091^{* * *}$ & $-.091^{* *}$ \\
\hline $\begin{array}{l}\text { Commitment } \rightarrow \\
\text { Conflict }\end{array}$ & - & & - & $-.037^{* *}$ & $-0.037^{* *}$ & - & $-.045^{* * *}$ & $-.045^{* *}$ \\
\hline $\begin{array}{l}\text { Interdependence } \rightarrow \\
\text { Performance }\end{array}$ & & + & & - & - & 0.016 & - & 0.015 \\
\hline $\begin{array}{l}\text { Trust } \rightarrow \\
\text { Performance }\end{array}$ & + & & & $.026^{* *}$ & 0.018 & - & - & - \\
\hline $\begin{array}{l}\text { Commitment } \rightarrow \\
\text { Performance }\end{array}$ & + & & + & 0.014 & 0.01 & - & - & - \\
\hline $\begin{array}{l}\text { Interdependence } \rightarrow \\
\text { Satisfaction }\end{array}$ & & + & & - & - & 0.017 & - & 0.014 \\
\hline $\begin{array}{l}\text { Trust } \rightarrow \\
\text { Satisfaction }\end{array}$ & + & & & $.053^{* *}$ & $0.038^{* *}$ & - & - & - \\
\hline $\begin{array}{l}\text { Commitment } \rightarrow \\
\text { Satisfaction }\end{array}$ & + & + & + & 0.016 & 0.008 & - & - & - \\
\hline $\begin{array}{l}\text { Interdependence } \rightarrow \\
\text { Trust Or Trust } \rightarrow \\
\text { Interdependence }\end{array}$ & + & + & & 0.011 & 0.009 & 0.008 & 0.007 & 0.008 \\
\hline $\begin{array}{l}\text { Interdependence } \rightarrow \\
\text { Commitment Or } \\
\text { Commitment } \rightarrow \\
\text { Interdependence }\end{array}$ & + & + & & 0.008 & 0.007 & 0.008 & 0.007 & 0.007 \\
\hline $\begin{array}{l}\text { Trust } \rightarrow \\
\text { Commitment }\end{array}$ & + & + & & $.061^{* *}$ & $.061^{* *}$ & $.061^{* *}$ & $.061^{* *}$ & $.061^{* *}$ \\
\hline
\end{tabular}

${ }^{\#}$ Note that some relationships are not hypothesized, often because of their indirect relations. We identify only the direct hypotheses reported in the literature.

${ }^{* *}$ Sig at $\mathrm{p}<.0$ 